\title{
FEMINISMO EN TIEMPOS DE CRISIS ${ }^{1}$
}

\author{
Lidia Falcón ${ }^{2}$
}

La crisis en que estamos inmersos está relacionada directamente con la llamada globalización, que con tanto entusiasmo han organizado las oligarquías políticas y económicas mundiales. Y ante la globalización y la crisis el feminismo tiene mucho que decir, porque representa los intereses no solo del cincuenta por ciento de la humanidad, sino de todos los seres humanos, ya que los hombres solo pueden salir ganando con el triunfo del feminismo frente a la explotación del capital y la rapiña de las especulaciones financieras. Porque, en definitiva, la única globalización es la del capital.

De la tríada de libertades de que presume la globalización: capitales, bienes y personas, únicamente se ha producido la de capitales. Los mismos países que exigen esa libertad, los países ricos, son los que ponen trabas a que los países del Tercer Mundo les exporten sus mercancías y servicios, y son los que se han fortificado como castillos, con policías, vigilancias, pasaportes y visados, vallas cuajadas de las llamadas concertinas cuchillas afiladas- para impedir que los emigrantes de los países pobres entren en sus territorios. Aunque éstos huyan de la miseria o de la persecución de dictaduras infames. Dictaduras que son apoyadas por los países “democráticos y libres”, porque a los tiranos

\footnotetext{
${ }^{1}$ Fecha de recepción: 01/12/2014.

Fecha de aceptación: 03/12/2014.

${ }^{2}$ Lidia Falcón es Licenciada en Derecho, en Arte Dramático y en Periodismo, además de Doctora en Filosofía. Destaca en el activismo feminista por ser la fundadora de las revistas Vindicación Feminista, y Poder y Libertad, así como por fundar y presidir el Club Vindicación, Vindicación Feminista Publicaciones, el Partido Feminista de España, la Confederación de Organizaciones Feministas y los Tribunales de Crímenes contra la Mujer. También en el terreno de las letras ha contribuido a la causa feminista con obras seminales (traducidas a varios idiomas) tales como: Mujer y Sociedad, Cartas a una idiota española, La Razón Feminista Tomos I y II, Violencia contra la mujer, Mujer y Poder Político, Los Nuevos Mitos del Feminismo y Los Nuevos Machismos; o libros de carácter autobiográfico como Los hijos de los vencidos, En el Infierno, Viernes y 13 en la calle del Correo, Memorias Políticas y La vida arrebatada. Su defensa de los derechos de las mujeres también se advierte en su extensa producción teatral y narrativa. Por todo esto y por su relevante participación en los principales foros internacionales de mujeres (Bruselas, Londres, Nairobi y Beijín), Lidia Falcón es una de las figuras más internacionalmente conocidas del feminismo español; $\square$ lidiafalcononeill@gmail.com.
} 
que gobiernan les venden sus productos, especialmente armamento para que repriman a sus propios pueblos o mantengan guerras de agresión contra sus vecinos.

El reparto de la riqueza en el mundo dice más que cualquier discurso ideológico. Estados Unidos, la Unión Europea, Canadá y Japón poseen alrededor del 75\% del Producto Interior Bruto mundial, pero representan menos del $20 \%$ de la población. Al mismo tiempo, una buena parte de la humanidad, entre el 50 y el 75\% es perdedora en el proceso de globalización, porque en el proceso de globalización se agudizan las causas estructurales de la pobreza y se beneficia a los que tiene más poder económico. En 1964, cuando estaba escribiendo mi libro “Los Derechos Laborales de la Mujer”, las estadísticas de la OIT decían que cincuenta millones de niños trabajaban en condiciones de extrema explotación, de esclavitud, en todo el mundo. Hoy, medio siglo más tarde, los niños explotados son 250 millones. Porque los países donde uno de cada dos niños no tiene instrucción, deben dedicar cuatro veces más a enjugar la deuda externa que a costear la educación de sus niños. Deuda que han contraído los tiranos de las dictaduras que los gobernaron, y que ahora tienen que pagar sus pueblos.

Los Países Menos Avanzados - eufemismo que sustituye a "países pobres"- en 1971 eran 25, hoy son 49, de los cuales 34 son africanos. Mientras la renta per cápita de los países ricos es de 25.000 dólares anuales, ninguno de los 49 alcanza los 900, y cuatro de ellos, Sierra Leona, Etiopía, República del Congo y Burundi, apenas llegan a los 150 dólares. Mientras el 80\% de la población del planeta no dispone de protección social, los países PMA reciben tan sólo el 0,5\% de las inversiones directas mundiales. Solo cinco países, Suecia, Noruega, Holanda, Luxemburgo, Dinamarca, aportan el 0,7 de su PIB a la ayuda a los países pobres. Los países de la OCDE, los más ricos del mundo, han reducido su aportación al desarrollo de los pobres, con sólo el 0,24\%. Mientras 160 millones de niños pasan hambre, la esperanza de vida en los países pobres ha pasado de 60 años en 1980 a 40 en la actualidad. Porque 2000 millones de personas no tienen acceso a las medicinas que necesitan para sus dolencias, 14 millones de niños mueren por enfermedades infecciosas y 45.000 diarios por desnutrición. 
En los últimos cinco años, los laboratorios farmacéuticos no han fabricado ningún medicamento destinado a combatir las enfermedades de los países pobres. La crisis producida por la enfermedad del Ébola ha puesto de manifiesto el abandono de los gobiernos europeos y estadounidense a las naciones africanas asoladas por la enfermedad, que únicamente han puesto en marcha planes de emergencia sanitaria e investigación farmacéutica cuando algunos de los sanitarios europeos o americanos han sido infectados.

Las cifras nos dicen que únicamente 630 millones de personas quieren entrar en el mercado global como productores y consumidores, es decir el 10\% de la población mundial. Y únicamente el diez por ciento de la población mundial disfruta de conexión a Internet, el $90 \%$ de la cual se encuentra en los países desarrollados. E1 50\% de las personas que habitan el planeta no han hablado nunca por teléfono y hay países que no disfrutan de conexión eléctrica.

La vergüenza del mundo es que las Conferencias de Naciones Unidas sobre Países Menos Avanzados (nuevo eufemismo), se celebran cada diez años, mientras los encuentros de organismos multilaterales financiados por los países ricos se celebran anualmente.

Pero no sólo en las extensas áreas del mundo no desarrollado encontramos el espectáculo de la miseria. En EEUU, el número de excluidos de los beneficios del sistema supera los 40 millones de personas y el salario obrero medio baja desde 1973. En Gran Bretaña, más de una cuarta parte de los niños no tiene acceso a los servicios públicos básicos; en Francia 6 millones de personas son radicalmente marginadas y el número de parados de larga duración crece a pesar del aumento del empleo. Actualmente, a un niño que se cría en un mal ambiente social le es cuatro veces más difícil que hace treinta años obtener buenos resultados en la enseñanza superior.

Cuando en 1994 escribí uno de mis libros sobre economía y trabajo, Trabajadores del Mundo, jrendios!, hallé las cifras de las inversiones que la Unión Europea iba a destinar a la asistencia social a los pobres, en el periodo de 5 años, de 1995 a 2000. Las aparentemente fabulosas cifras que ofrecían, divididas por los cincuenta millones de pobres que sobreviven en los territorios de la Unión, en el lustro que debía durar aquel 
plan de ayuda, daban como resultado que a cada pobre se le destinaban $¡ 70$ pesetas! (50 centavos de dólar) por año.

¿Pero, en realidad, a quien beneficia la conexión por Internet? Únicamente a una minoría de habitantes del mundo, que poseen conexión eléctrica y de fibra óptica y tienen conocimientos suficientes para saber utilizarlo. A este respecto, recuerdo la parodia que un amigo mío, actor, realiza, con exquisito humor, sobre el ama de casa española de clase trabajadora que se levanta cada mañana, enchufa el ordenador y antes de salir de casa con su bolsa de la compra para ir al mercado a adquirir la comida del mediodía consulta los precios del pollo en los mercados de Turquía, de Bélgica o de Portugal.

Una patética muestra del comportamiento irracional de las instituciones internacionales dedicadas a la ayuda al Tercer Mundo, me la contó una amiga que había visitado el Congo. Encontró en un poblado perdido en la selva un hospital levantado con fondos de la OMS. Se trataba de un magnífico edificio que poseía las mejores instalaciones. Tenía una enorme cocina ultra moderna: grandes hornos eléctricos, frigoríficos y neveras, quemadores y planchas... Y el hospital solo disponía de dos horas al día de corriente eléctrica para los quirófanos. La comida diaria la cocinaban las mujeres de los enfermos en unas pequeñas hogueras de leña que encendían en el patio del hospital al aire libre. Mientras la ONU y la FAO y la OMS realizan grandes obras faraónicas en el Tercer Mundo, como el hospital citado- hay que sospechar que con el beneficio de suculentas comisiones para los promotores, arquitectos, constructores e intermediarioslas mujeres de esos países deben recorrer enormes distancias, en las que invierten tres o cuatro horas diarias, para abastecerse de agua.

En definitiva, la globalización consiste en la sustitución de la política por la economía, de la democracia por los mandatos del mercado. En la imposición de un modelo de poder económico mundial controlado por las más poderosas compañías y consorcios multinacionales. La consolidación del pensamiento único neoliberal y sus dogmas económicos, como marco ideológico al que habrán de adaptarse instituciones políticas, parlamentos, partidos, sindicatos, colectivos sociales, sociedades e individuos. 
Hablar de la sustitución de la economía por la política es una fórmula solo buena para espíritus simples y pueblos ingenuos. Es preciso recurrir a Marx -aunque ya Jenofonte habla de que la economía condiciona el gobierno de los pueblos- para saber que el capitalismo es el sistema económico que se implanta con el único propósito de obtener los mayores beneficios. Nunca en la historia de la humanidad se había obtenido una semejante acumulación de capital y de beneficios por parte de las empresas. Y no solo a base de extraer plusvalía a los trabajadores, como explicaba Marx del capitalismo clásico e incipiente. En la actualidad la especulación, la estafa, la falsificación de los productos ha sustituido al viejo sistema productivo de mercancías que se realizaba bajo las normas del puritanismo burgués que describe Max Weber. El caso de la estafa de la empresa energética Enron, la burbuja financiera en el capital especulativo e inmobiliario como la quiebra de Lehman Brothers y el rescate multimillonario de Goldman Sachs, entre muchos otros casos, la infección sanitaria con la conspiración de las "vacas locas" en Europa, el tráfico de armas, el de drogas y el de personas: emigrantes y mujeres y niños para la prostitución, constituyen enormes porcentajes de los beneficios totales del capital. Pues bien, la llamada política de derechas o conservadora no está dirigida más que a mantener o conservar estos beneficios. La política siempre al servicio de los intereses de las oligarquías imperialistas, casi desaparecidas las burguesías nacionales, fagocitadas o compradas por los grandes poderes económicos multinacionales.

La democracia actual está organizada para preservar el poder de esos grupos económicos. Así, los sistemas electorales, cuyos complicados resortes están astutamente pensados para evitar toda competencia a los partidos mayoritarios por parte de partidos o grupos sociales críticos, tanto en Estados Unidos como en la plural España. El Partido Feminista tiene buena experiencia sobre este tema a partir de su participación en las elecciones al Parlamento Europeo de 1999.

Durante los últimos dos siglos, desde la Revolución Francesa, las luchas populares lograron arrancar algunas conquistas sociales. La globalización ha supuesto el fin de las mismas. Los trabajadores ya no tienen derechos. Se acabaron las garantías jurídicas que aseguraban la jornada de ocho horas, las vacaciones pagadas, la estabilidad en el empleo, 
las pensiones y la sanidad pública. Se implanta el imperio de las multinacionales y las explotaciones económicas sobre toda clase de personas.

El panorama mundial de la globalización significa que las multinacionales operan en todo el planeta, extrayendo el mayor beneficio de sus actividades económicas, que consisten en producir en los países pobres donde la fuerza de trabajo es esclava, vender en los ricos a precios infinitamente superiores, y mantener la sede social en los paraísos fiscales para no pagar impuestos. Con detalle describo esta situación mundial en mi libro “Trabajadores del Mundo, ¡rendíos!”.

\section{¿Y qué hay de las mujeres?}

Ciertas informaciones falaces y tendenciosas aseguran que la globalización opera en beneficio de las mujeres, asegurando su avance en todos los países. Según esta doctrina los derechos democráticos conquistados por el Movimiento Feminista en occidente, tras dos siglos de esforzadas luchas, se aplicarían automáticamente a las mujeres de los países subdesarrollados, sometidas hasta ahora a toda clase de vejaciones, humillaciones e indignidades. En contra de estas afirmaciones se yergue la tozuda realidad.

La IV Conferencia de Beijín, de 1995, resulta el mejor ejemplo de la falsedad de estas afirmaciones. Las cifras que ofrecen las organizaciones internacionales sobre los males que padecen las mujeres y los niños en este cruel planeta no han mejorado ni en un decimal en este último lustro. Por el contrario, en según qué aspectos han empeorado. De los mil trescientos millones de pobres el ochenta por ciento son mujeres, de los mil millones de analfabetos el ochenta por ciento son mujeres; mueren por desnutrición más niñas que niños porque su comida se la dan a sus hermanos varones; los abortos selectivos de hembras y el infanticidio femenino ha ocasionado un déficit de mujeres en todo oriente de cien millones de mujeres. Se practica a las niñas la cliteridectomía, la mutilación de los labios menores, se las infibula, se las apalea, se las mata por honor, se las lapida por adulterio, se quema a las jóvenes esposas para cobrar la dote, se quema a las viudas en la 
pira del marido, se las vende como esclavas para el trabajo y para la prostitución, en las mismas condiciones y peores que antes de Beijín. En Nicaragua miles de personas, sobre todo mujeres y niños, buscan en los basureros para poder comer, en India, en Pakistán, los niños soportan jornadas de doce y catorce horas encerrados en locales sin ventilación anudando alfombras para cobrar dos dólares al día. En Filipinas, en Tailandia, las niñas son vendidas para la prostitución a los ocho años y sobreviven en los burdeles hasta los veinte, en que mueren de SIDA en plena calle.

¿En dónde, pues, los beneficios de aquella magna conferencia, que hoy todavía siguen publicitando los gobiernos y organizadores que asistieron? ¿En dónde, pues, los beneficios de la globalización, que debería llevar el desarrollo y el bienestar a todo el globo? El título de la Conferencia de Beijín era el de "Igualdad, Desarrollo y Paz", pero inmediatamente el concepto de igualdad fue sustituido por el de equidad, ante la presión de los países islámicos que no quieren ni oír que sus mujeres pudieran tener un trato igual que los hombres. Según la postura de los musulmanes conservadores, "la Conferencia forma parte de una serie de tentativas encaminadas a imponer un estilo de vida contrario a los valores religiosos y a las barreras morales, que han impedido a muchos pueblos caer en la depravación sexual y en el desequilibrio psicológico". Con ésta declaración quedaban claras sus intenciones.

Apenas comenzada la Conferencia, términos fundamentales en materia de derechos humanos, derechos en materia sexual, derechos de las jóvenes, violencia contra las mujeres, desigualdad económica, salud reproductora, trabajo, igualdad legal y política, derechos familiares, aprobados en el documento llamado Plataforma de Acción, fueron puestos en cuestión por el grupo de países confesionales, y sólo veinticuatro horas más tarde del término de la Conferencia ciento cuarenta y siete países afirmaron que se negarían a cumplir sus cláusulas.

Veinte años después de aquella efemérides, y ahora se aprestan todos los gobiernos a conmemorar tan fausto aniversario, únicamente ocho países cumplen el protocolo de Beijín. Que al ser los más avanzados del planeta igualmente los hubieran cumplido sin que los acuerdos de Beijín los obligaran. Uno de ellos, por supuesto, Suecia. Pero allí, en 
el Paraíso de las mujeres, hace algunos años se constituyó un Partido Feminista, llamado Iniciativa Feminista, por las mismas mujeres políticas que habían militado en el Partido Socialdemócrata, que incluso habían sido diputadas y portavoces del partido, y en el Manifiesto de constitución plantean las mismas reivindicaciones que el Partido Feminista de España o las plataformas del Movimiento de nuestro país. La violencia, las diferencias salariales, la marginación del poder político, contra la mujer, están también presentes en la sociedad sueca.

En la actualidad, en todos los países musulmanes las mujeres tienen menos derechos que los hombres. En países donde se lapidan mujeres y se permite la poligamia, el repudio, la cliteridectomía, la infibulación, la venta de esposas, el matrimonio infantil, donde la hija solo tiene derecho a la mitad de la herencia de su hermano varón, donde las niñas no reciben la misma educación que los varones y las mujeres no pueden trabajar, y se practican las ejecuciones públicas, es imposible para sus gobernantes implantar la igualdad entre sexos. Así, todos los días en el norte de Nigeria, en Irán, en Afganistán, en Irak, en Somalia, son azotadas, encarceladas y lapidadas mujeres después de haber sido violadas, acusadas de vida deshonesta o de adulterio.

Al mismo tiempo, las multinacionales utilizan la fuerza de trabajo femenina e infantil en el Tercer Mundo para producir toda clase de productos, mediante la más escandalosa explotación. Entonces, ¿en que beneficia a mujeres y niños la globalización? Pueden beber Coca-Cola.

En realidad la situación hoy es peor que hace veinte años cuando se celebró la IV Conferencia de la Mujer en Beijín. El fundamentalismo islámico se extiende sin freno por todo el mundo musulmán y allí donde se implanta y crece se impone una mayor represión contra las mujeres. En Marruecos, en Egipto, en Siria, en Irak, en Libia, hace veinte años las mujeres vestían sin restricciones, trabajaban en muchas áreas de la producción, estudiaban en aulas mixtas tanto en la escuela primaria y secundaria como en la universidad. En la actualidad la visión de mujeres envueltas en tristes velos negros o grises, incluso con la cara tapada, llena las calles de esos países, y no se las ve ejerciendo casi ninguna actividad remunerada. 
El terrible retroceso que sufrieron las mujeres en Afganistán después del triunfo de los talibanes y en Irán tras la llamada "revolución islámica" no es un secreto para nadie. Y no se puede vislumbrar un cambio positivo en breve tiempo. En Irak, bajo el mandato de Sadam Husein las mujeres trabajaban en casi todas las profesiones, vestían sin prohibiciones y disfrutaban de unas leyes igualitarias. Hoy están tapadas de los pies a la cabeza y marginadas del trabajo, la educación y la política.

En Afganistán bajo el mandato soviético las mujeres podían ejercer todas las profesiones, vestían sin prohibiciones y disfrutaban de unas leyes igualitarias. Hoy están ahogadas debajo de los burkas, marginadas del trabajo, de la enseñanza y de la política, perseguidas, apaleadas y asesinadas, sin que la "comunidad internacional" considere que debe intervenir como hizo contra el régimen de apartheid de Sudáfrica.

Esta horrible situación actual ha sido provocada precisamente por esa "comunidad internacional" que liderada por EEUU y la UE pretende que está extendiendo la democracia en todo el planeta. El objetivo de destruir el comunismo llevó a EEUU a organizar y financiar los grupos islámicos más fanáticos para que lucharan contra la URSS en el terreno de Afganistán. Después ha seguido la invasión de Irak, las guerras de Libia y de Siria, la perversión de las rebeliones llamadas de la "primavera árabe". La amenaza islámica no es tan temible para el imperialismo como la extensión de los movimientos obreros -véase el caso de Egipto- y la posibilidad de que en el Medio Oriente se instauraran gobiernos socialistas. El resultado de las operaciones militares y de inteligencia de EEUU, con el apoyo de las potencias europeas, ha sido la destrucción entera de países, la extensión de la pobreza, la persecución de minorías étnicas y religiosas, millones de personas desplazadas y la represión mayor contra la mujer.

España no pertenece al Tercer Mundo pero su participación en la Unión Europea no la ha llevado a alcanzar la media de los rankings europeos. Todavía como herencia de la dictadura tiene el mayor número de amas de casa de Europa, 5.500.000, que no perciben salario ni disfrutan de seguridad social, vacaciones ni jubilación. El porcentaje de población activa femenina es el más bajo también, con el 54\%, frente al 75\% de Francia y el $82 \%$ de Suecia, y de ellas el paro alcanza hoy el $27 \%$. Las mujeres ganan el $30 \%$ por 
ciento menos que los hombres por el mismo trabajo y los puestos de dirección en las empresas privadas no alcanzan el 6\%, en la Administración pública son el 12\%. Al mismo tiempo la violencia contra las mujeres se cobra de 75 a 80 víctimas cada año, y se cuentan 2.600.000 mujeres maltratadas sistemáticamente. El índice de violaciones, acoso sexual, abuso de menores ni siquiera existe, y se supone que no se denuncian más que el $10 \%$. Los niños y las niñas asesinadas no se cuentan.

En educación se ha avanzado de manera notable, tanto en la escolarización general como en la femenina. Las estadísticas oficiales aseguran que el 100\% de los niños están escolarizados, pero en la etnia gitana se produce el mayor número de analfabetismo, absentismo escolar y abandono de la escuela, especialmente entre las niñas. El 80\% de ellas abandona la escuela al comenzar la enseñanza secundaria. Y todavía contamos con 800.000 personas analfabetas, la mayoría mujeres. En la Universidad, mientras las mujeres representan el 60\% de los estudiantes en las Facultades de Humanidades, solo están presentes en el 15\% de los licenciados en Ingeniera y Teconología. Mientras el $18,7 \%$ de las mujeres con títulos universitarios están desempleadas, los hombres solo constituyen el $6,8 \%$.

En cuanto al grave problema de compatibilizar el trabajo y el cuidado de los hijos y del hogar, las estadísticas oficiales no dejan lugar a dudas. Las mujeres dedican más de 5 horas a los trabajos domésticos y los hombres 1,5. Y en esas tareas cuentan el cuidado del coche y el paseo del perro.

Mientras tanto, como en todo el mundo, las mujeres siguen siendo las más pobres.

El reparto de la renta en España es del 18\% para las mujeres y del $82 \%$ para los hombres.

\section{El feminismo debe conquistar la felicidad}

Así, pues, comprobamos, que en el año 2014 miles de millones de seres humanos padecen hambre y marginación, y que las mujeres son las víctimas de este injusto reparto 
de los bienes del mundo y de la opresión a que las someten los hombres de su misma clase social. Hemos visto cómo ni los avances técnicos ni el aumento del nivel de vida en los países ricos las han liberado de cumplir con su especialidad reproductora; que las dos terceras partes de las mujeres del mundo viven en la miseria y que sus condiciones de explotación, ausencia de educación, carencia de alimentación y falta de salud no se han remediado.

Ha llegado pues la hora de que seamos las mujeres, a través del feminismo, las que tomemos un papel protagonista en la tarea de erradicar las opresiones y las explotaciones que se suceden en el mundo y que son causa de las más profundas infelicidades de los seres humanos.

Porque las feministas tienen la obligación de elaborar una ideología que no sólo defienda los intereses de las mujeres sino que plantee también la transformación del mundo. Han de manifestarse en contra del "pensamiento único", de la dominación capitalista e imperialista que se ha impuesto y que encubre sus propósitos depredadores, sus tácticas de invasión de otros países - tanto por las armas como comercialmente- con eufemismos del lenguaje como "globalización” y "aldea global”. Han de tomar sobre sí el propósito de oponerse a todas las explotaciones, a todas las opresiones, a todas las injusticias.

Las mujeres deben ser las protagonistas de su lucha, como toda clase tiene la responsabilidad de liberarse de sus cadenas. Y no solamente en defensa de sus intereses, sino de los de toda la humanidad. El feminismo es una ideología filosófica, un movimiento social y un programa político. El feminismo es el último de los grandes movimientos liberadores llegados a la escena de los últimos siglos. Es superador de los socialismos que los hombres han defendido en los que tantas veces no han incluido a las mujeres. Porque el feminismo no solamente se ha ocupado de los intereses económicos, sino que elabora los nuevos moldes morales que deben regir las relaciones humanas en los terrenos más personales e íntimos: la familia, la maternidad, la amistad, el amor, la sexualidad. El feminismo es una teoría progresista y liberadora que pone los cimientos 
del edificio moral que está por construir, para asegurar el pacífico y justo desarrollo humano.

Al mismo tiempo, es imprescindible comprender que el feminismo no es un determinismo biologista, sino una ideología revolucionaria que es preciso construir y asimilar y difundir. No se es feminista por el hecho de ser una hembra preparada para reproducirse, sino por un largo trabajo de concienciación, de estudio, de reflexión, por un sentimiento de rebeldía ante las desigualdades del mundo, por un altruista deseo de reparar las injusticias cometidas y de compensar a las víctimas. Tantas veces sin ser a la vez víctima de ellas.

Para convertir a las mujeres -y a los hombres también- en los "sujetos de virtud" que desearíamos, hace falta una larga labor de concienciación feminista. Nada se construye en el mundo humano sin trabajo y esfuerzo. Los movimientos revolucionarios no lograron los avances sociales y morales de que disfrutamos más que después de largos años de luchas, de organización, de sacrificios personales.

Lo que sí es cierto es las feministas no nacen sino que se hacen, y lograr que se hagan feministas las mujeres -y los hombres- ha de ser una larga tarea que no se realiza sentándonos en mitad del camino a ver pasar a los demás, sintiéndonos tan contentas de nosotras mismas por haber nacido con ovarios y matriz.

Lo que nosotras entendemos por feminismo debe hacerse cargo de la liberación de toda la humanidad, de todas las personas. Ese es el objetivo final del feminismo. Del feminismo universalista, no particularista, que rechaza las tendencias reductoras actuales de un feminismo que se sitúa en un espacio mínimo de los objetivos sociales y políticos por los que tenemos que luchar todos los seres humanos. No es suficiente con reclamar pequeñas mejoras para la vida cotidiana, fundamentalmente para las mujeres blancas, de clase media de los países más desarrollados. El feminismo reduccionista que impera en Europa y Estados Unidos, se ha apartado de las denuncias y reivindicaciones más fundamentales en el terreno de la política y de la economía, considerando que éstas eran cuestiones de los hombres. Es de destacar la dicotomía que se establece continuamente entre feminismo y política. Mientras no se entienda que el feminismo contiene en su 
ideología y en su práctica, la denuncia de todas las opresiones y la defensa de todos los oprimidos, no haremos más que una pequeña labor de asistencia social, de la que será beneficiada una muy pequeña parte de mujeres. Si las feministas no creen que forman parte de un mundo aparte, que debe ser protegido para no contaminarse con los defectos de los restantes individuos, tienen la obligación de preocuparse de todas las miserias que afligen hoy a la humanidad.

En los años en que se reunía en Porto Alegre el Foro Antiglobalización he echado de menos una participación relevante de las feministas. Las denuncias y reivindicaciones planteadas en ese foro han tenido siempre como protagonistas a los hombres, y tanto el tono como el lenguaje, como la jerarquía de los temas planteados han correspondido al estilo y a las prioridades masculinas. Resulta desolador que en la relación de desdichas que ocasiona la globalización en el mundo, no se especifique que las mujeres son las más perjudicadas, y que la denuncia de la opresión machista se limite a mencionar la violencia doméstica en el último lugar de las conclusiones. Estamos aceptando nuevamente el liderazgo masculino en todos los movimientos de oposición al sistema, y seguimos siendo las fieles ayudantes de los hombres, teniendo en cuenta el gran número de mujeres que han participado en todos los Foros de Porto Alegre.

Falta el protagonismo del feminismo en los movimientos de oposición al armamentismo, a la OTAN, a las guerras de invasión, a los grandes consorcios y a las instituciones multinacionales, en todos los Foros internacionales que el movimiento antiglobalización ha organizado. En otro caso, mantendremos el segregacionismo del Movimiento Feminista como un movimiento dedicado exclusivamente a las reivindicaciones parciales a favor de algunas mejoras para las mujeres, que además no deberían entenderse únicamente femeninas sino concernientes a toda la humanidad.

Para llevar a cabo este objetivo, es imprescindible que el Movimiento Feminista se convierta en un movimiento político. El desafío para este siglo que comienza es ver cómo las mujeres asumen su conciencia de clase luchando por sus intereses desde sus propias organizaciones políticas. Sin imitaciones ni sometimientos al poder masculino; estableciendo sus tácticas de lucha y compitiendo en la arena electoral para situar a sus 
dirigentes en los organismos estatales. Se trata, por primera vez, no de suplicar un puestecito en las organizaciones masculinas sino de organizarse autónomamente desde el feminismo.

Al mismo tiempo, comprobamos la marginación de las mujeres en las cúpulas directivas de los partidos, incluso los más progresistas. Observamos los patéticos esfuerzos de las afiliadas a esos partidos para ser consideradas con el mismo respeto y consideración de sus compañeros. Tenemos ya los resultados de la aplicación de diversas reformas en España: cuotas, discriminación positiva, paridad, igualdad, y sus escasos éxitos. La aplicación de la ley de igualdad ha logrado que en las primeras elecciones al Parlamento español inmediatamente después de aprobada la ley hubiera dos mujeres menos que en la legislatura anterior. Y nos planteamos si no ha llegado el momento, como dice Suzanne Blaise, de no seguir rogándoles a los hombres que se hagan cargo de nuestra liberación.

Las mujeres deben ser las protagonistas de su lucha, como toda clase tiene la responsabilidad de liberarse de sus cadenas. No olvidemos la máxima de que "la liberación de una clase es obra de la clase misma". Las mujeres que no han comprendido todavía que deben aplicarse a sí mismas esta consigna se hallan en un nivel muy atrasado de concienciación. Siguen confiándoles a los hombres su propio destino, como lo hicieran las niñas al padre y más tarde al marido.

Las mujeres deben dotarse de partidos feministas con los que defender sus intereses; partidos en sentido político de la palabra, ya que sin la estructura, la organización y un programa que reivindique las reformas y cambios precisos a corto y medio plazo para mejorar su propia vida y la de las demás clases sometidas a condiciones injustas, no tendrán posibilidad de alcanzar el poder que les permita participar en las decisiones que dirigen el mundo.

Pero estos partidos feministas tienen la obligación de elaborar una ideología que no sólo defienda los intereses de las mujeres sino que plantee también la transformación del mundo. Han de manifestarse en contra del "pensamiento único", de la dominación capitalista e imperialista que se ha impuesto y que encubre sus propósitos depredadores, 
sus tácticas de invasión de otros países - tanto por las armas como comercialmente- con eufemismos del lenguaje como "globalización” y "aldea global". Han de tomar sobre sí el propósito de oponerse a todas las explotaciones, a todas las opresiones, a todas las injusticias. Si las feministas no creen que forman parte de un mundo aparte, tienen la obligación de preocuparse de todas las miserias que afligen hoy a la humanidad.

Pero para convertir a las mujeres -y a los hombres también- en los "sujetos de virtud" que desearíamos, hace falta una larga labor de concienciación feminista. Nada se construye en el mundo humano sin trabajo y esfuerzo. Los movimientos revolucionarios no lograron los avances sociales y morales de que disfrutamos más que después de largos años de luchas, de organización, de sacrificios personales.

Desde el Partido Feminista exigimos unas reformas políticas y económicas inmediatas en España para paliar los devastadores efectos de la actual crisis. Reformas que se inscriben únicamente en el ideario del Estado del bienestar capitalista, ya que la revolución feminista y socialista está todavía lejos. Para ello debemos proceder a:

1- La nacionalización de la banca, que ha provocado la crisis económica con sus espurias actuaciones, muchas de ellas delictivas, pero a la que se están dedicando la mayor parte de los recursos económicos del país.

2. Renegociar la deuda estatal, con una auditoría que explique qué parte de la deuda corresponde a maniobras delictivas y proceder a una quita y espera de la misma.

3- Derivar los recursos destinados a la compra de armamento para atender las necesidades sociales.

4- Aumentar y recrear la red de servicios públicos, en todos los sectores: educación, sanidad, guarderías infantiles, centros geriátricos, transporte, vivienda, que será fundamental para ampliar el empleo femenino.

5- Aumentar el salario mínimo interprofesional.

6- Aumentar la cobertura del paro. 
7- Reformar la educación y la investigación científica para que sean protagonistas de la producción española, centrada hoy en los sectores de la construcción y el turismo, con la pobreza que tal situación supone.

8- Reindustrializar sectores de producción que han sido desmantelados y apoyar la agricultura y la ganadería que se han destruido por las órdenes de la Unión Europea, y que nos ha situado entre los países de servicios, es decir servidores de los jubilados alemanes.

9- Reforma fiscal para que las grandes fortunas y las multinacionales sean los que paguen la mayor parte de los recursos del Estado.

10- Perseguir eficazmente el fraude fiscal.

11- Plantear seriamente en Europa acabar con los paraísos fiscales.

12- Perseguir eficazmente el tráfico de armas, el tráfico de personas, el tráfico de estupefacientes.

13- Abolir la prostitución.

14- Perseguir eficazmente la violencia contra la mujer y los niños.

15- Reformar la Justicia española para que realmente pueda ser eficaz y justa.

16- Reformar las cárceles para que no sean la proscripción de los pobres.

Pero ninguna de estas reformas ni avances pueden realizarse en España sin que se produzca un cambio fundamental en la forma de Estado. Sin que se proclame la III República y se acabe definitivamente con la Monarquía es imposible acabar con la corrupción generalizada de ciertos dirigentes políticos y económicos, cuyo germen y base se encuentran en la Casa Real aliada con los grandes poderes: la Iglesia, el Ejército, la burguesía industrial, los latifundistas del sur, que se oponen a cambiar el régimen que se instauró el año 1978 en España. Solo con la República podremos empezar a construir la democracia política, social y económica en nuestro país.

Madrid, 1 de diciembre de 2014. 